Pacific Journal of Mathematics

THE SPACE OF BOUNDED SEQUENCES WITH THE MIXED 


\title{
THE SPACE OF BOUNDED SEQUENCES WITH THE MIXED TOPOLOGY
}

\author{
AJIT KaUR ChILANA
}

\begin{abstract}
The space of bounded sequences with the mixed topology has some interesting properties and can be used to answer two questions on boundedly generated spaces asked by $T$. Ito and T. Seidman.
\end{abstract}

1. Introduction. We consider the locally convex algebra $m$ of bounded complex sequences with pointwise addition and multiplication equipped with the mixed topology [11]. The topology $\tau$ is the same as the strict topology $\beta[1]$ on $C(S)$, when $S$ is taken to be the space of positive integers. This space has a number of interesting properties, some of which can be found in [11], [3] (Example 3), [1], and [4]. In this note we obtain some further results such as: this space is hereditary boundedly generated [6], it has an unconditional Schauder basis, and its Gelfand map is continuous.

The basic ideas are as in [7]. A locally convex space $E$ is said to be boundedly generated, in short, $B G$ if it is the closed linear span of a bounded subset; it is said to be hereditary boundedly generated, in short, $H B G$, if every closed linear subspace of the space is $B G$ [6]. $E$ is called sequentially barrelled if every $\tau_{s}\left(E, E^{\prime}\right)$-null sequence in the topological dual $E^{\prime}$ of $E$ is equicontinuous [10]. The sequential dual $E^{+}$of $E$ is the set of sequentially continuous linear functionals $f$ on $E$ (i.e., $f\left(x_{n}\right) \rightarrow 0$ whenever $x_{n} \rightarrow 0$ in $E$ ) [10]. $E$ is called semi 1-barrelled if every $\tau_{s}\left(E, E^{\prime}\right)$-bounded sequence in $E^{\prime}$ is equicontinuous [3]. A barrel in a locally convex algebra $E$ that is also an idempotent set (i.e., $A \subset E$ such that $A . A \subset A$ ) is called an $m$-barrel and $E$ is said to be $m$-barrelled if every $m$-barrel in $E$ is a neighborhood of 0 [8]. Let $E$ be a complex locally convex algebra. Let $M$ denote the set of nonzero, continuous, multiplicative, linear functionals on $E$, provided with the weak topology induced by $E$. Let $C(M)$ denote the space of complex continuous functions on $M$ with the topology of compact convergence. The Gelfand map $G$ on $E$ to $C(M)$ is given by $G(x)(m)=m(x)(x \in E, m \in M) . \quad E$ is called strongly semi-simple if $G$ is an algebraic isomorphism of $E$ into $C(M)$.

Now let $E$ denote the space $m$ with the mixed topology $\tau$ or, equivalently, the strict topology $\beta$. A base of $\tau$-neighborhoods of 0 is given by

$$
\mathscr{U}=\left\{U_{a}=\left\{x=\left(x_{n}\right):\left|x_{n}\right| \leqslant a_{n}, n=1,2, \cdots\right\}, a=\left(a_{n}\right), 0<a_{n} \rightarrow \infty\right\} .
$$


Let $B=\left\{x \in E:\left|x_{n}\right| \leqslant 1, n=1,2, \cdots\right\},\|x\|=\sup \left\{\left|x_{n}\right|: n=1,2, \cdots\right\}$ for $x \in m$. Let $e^{i}=\left(x_{n}\right): x_{i}=1$ and $x_{n}=0$ if $i \neq n$. Let

$$
l^{1}=\left\{x \in m: \sum_{n=1}^{\infty}\left|x_{n}\right|<\infty\right\},
$$

and $\|x\|_{1}=\sum_{n=1}^{\infty}\left|x_{n}\right|\left(x \in l^{1}\right)$. The $\alpha$-dual of $m$ is $l^{1}$ ([7], $\left.\S 30.1\right)$ and $\left(m, l^{1}\right)$ is thus a dual pair.

2. Properties of the space $E$.

I. $E$ is complete and has the Mackey topology $\tau_{k}\left(l^{1}\right)$.

It is proved in [1] (also in [3]) that $E$ is complete. The second part follows from [4], Theorems 2 and 4, on taking $S$ to be the set of positive integers with the discrete topology.

II. No topology on $m$ compatible with duality is barrelled or $m$ barrelled.

The set $B$ is a barrel [3] and not a neighborhood in $E$, also it is idempotent. As $E$ carries the strongest topology compatible with duality and barrels remain barrels under any topology compatible with duality, the result follows immediately.

III. $E$ is an $H B G$ space.

For any subspace $F$ of $E, F=\bigcup\{n(B \cap F): n=1,2, \cdots\}$ and, therefore, $F$ is the closed linear hull of a bounded subset of itself.

REMARK 1. It was asked in question (2) of [6], if there are any $H B G$ spaces that are not Banach or separable Fréchet spaces. II and III give an affirmative answer.

REMARK 2. In [2] the first part of question (3) in [6] was answered in the negative and the following more general question was raised: If $F$ is a $B G$ space with dual $F^{\prime}$, then must there be a barrelled topology compatible with duality $\left(F, F^{\prime}\right)$ ? The example given there to prove that the answer is "No" is artificial in the sense that its completion is a Banach space and thus barrelled. By I, $E$ is a complete space and II and III show that it serves as a better example.

IV. A sequentially continuous linear functional on $E$ is continuous and $E$ is sequentially barrelled.

Combining [5], Theorem III (2.8) and I above, we have $E^{\prime}=E^{+}$. Thus $\tau=\tau_{k}\left(E^{+}, E\right)$. Proposition 4.3 in [10] then gives that $E$ is sequentialy barrelled. 
V. $E$ is not semi 1-barrelled.

Consider $A=\left\{e^{n}: n=1,2, \cdots\right\} \subset l^{1}=E^{\prime}$. For each $x \in E$, and for $n=1,2, \cdots,\left|e^{n}(x)\right|=\left|x_{n}\right| \leqslant\|x\|$. So $A$ is $\tau_{s}\left(E^{\prime}, E\right)$-bounded. Also the polar $A^{\circ}$ of $A$ in $E$ is $B$ which is not a neighborhood. Therefore, $A$ is not equicontinuous.

Remark 3. It is known ([3], Proposition 9 (ii), p. 481) that a semi 1-barrelled space is sequentially barrelled. IV and $\mathrm{V}$ show that the reverse implication may not be true. We take this opportunity to point out that there are two Proposition 9 in [3] (!) and in Proposition 9 (ii) on p. 481 [3] it should be almost semi-1-barrelled instead of almost semi-barrelled.

VI. E has a Schauder basis $\left(e^{n}\right)$, which is

(i) bounded multiplier,

(ii) boundedly complete,

(iii) not of type $P^{*}$,

(iv) unconditional,

(v) shrinking,

(vi) not of type $P$,

(vii) monotone, and

(viii) e-Schauder [5].

We note that $m$ is perfect and normal ([7], $\S 30.1), E^{\prime}=l^{\prime}=m^{\times}$ and $\tau=\tau_{k}\left(l^{1}\right)$. We can use [5], I (2.5) to obtain (i), (ii), and (iii). To prove (iv) we appeal to [5], I (2.4) and (i) above. The strong dual of $E$ is $\left(l^{1},\|\cdot\|_{1}\right)$ and it has $\left(e^{n}\right)$ as a Schauder basis, so (v) is true. For (vi) note that $e^{n} \rightarrow 0$ in $E$. Also $\mathscr{C}$ satisfies the conditions for $\left(e^{n}\right)$ to be monotone and $S_{N} U_{a} \subset U_{a}$ for all $U_{a} \in \mathscr{L}$ and $N=1,2, \cdots$. Thus (vii) and (viii) are true.

REMARK 4. It is well-known that $m$ with the sup-norm topology is not separable and thus cannot have a basis. The above result shows the difference a change in the topology can make.

VII. $C(M)$ is barrelled.

Let $0 \neq f \in l^{1}$ and $f$ be multiplicative on $E$. Because

$$
x=\lim _{n \rightarrow \infty} \sum_{j=1}^{n} x_{j} e^{j},
$$

$f(x)=\lim _{n \rightarrow \infty} \sum_{j=1}^{n} x_{j} f\left(e^{j}\right)$ for each $x \in E$. So there is an $n$ such that $f\left(e^{n}\right) \neq 0$. Also $f\left(e^{n}\right)=f\left(e^{n} e^{n}\right)=f\left(e^{n}\right) f\left(e^{n}\right)$, so we must have $f\left(e^{n}\right)=1$. Now for $j \neq n f\left(e^{n}\right) f\left(e^{j}\right)=f\left(e^{n} e^{j}\right)=f(0)=0$, so $f\left(e^{j}\right)=0$. Thus $f(x)=x_{n}$ and $f$ can be identified with $e^{n} \in l^{1}$. So 


$$
M=\left\{e^{n}: n=1,2, \cdots\right\} .
$$

Also $\{x\}^{\circ} \cap M=\left\{e^{n}\right\}$ if $x \in m$ be such that $x_{n}=1$ and $x_{j}=2$ for $j \neq n$. Hence $M$ can be identified with the set of positive integers with the discrete topology. Therefore, $C(M)$ is the space of all complex sequences with the topology of pointwise convergence and is, thus barrelled.

REMARK 5 . We note that $m$-barrelledness of some topology compatible with duality is sufficient in [8], Lemma 3.1 (or [9], Cor. 6.3) and even this condition is not necessary as shown by II and VII.

VIII. E has jointly continuous multiplication.

If $a=\left(a_{n}\right)$ be such that $0<a_{n} \rightarrow \infty$ then for $b=\left(b_{n}\right)$, where $b_{n}=a_{n}^{1 / 2}, 0<b_{n} \rightarrow \infty$ and also $U_{\iota} U_{b} \subset U_{a}$.

IX. The Gelfand map is continuous but not a homeomorphism.

It is immediate from the proof of VII.

The next result shows that $E$ does not, however, have a good functional representation.

X. E cannot be embedded algebraically and topologically in a $C(X)$ for $X$ a locally compact Hausdorff space or for $X$ a completely regular Hausdorff space.

From the proof of VII we get that $G$ is an isomorphism of $E$ into $C(M)$, and thus $E$ is strongly semi-simple. Also in view of VIII, $E$ is a topological algebra in the sense of [9]. Combining Theorem 4.6 of [9] and IX above we get the required result.

REMARK 6. This space also helps in distinguishing some classes of topological algebras such as $m$-k-barrelled algebras, $m$ - $k$-infrabarrelled algebras, locally boundedly multiplicatively convex algebras.

I should like to thank the referee for his suggestions regarding the format of the paper.

\section{REFERENCES}

1. R. C. Buck, Bounded continuous functions on a locally compact space, Michigan Math. J., 5 (1958), 95-104.

2. A. K. Chilana, Invariant subspaces for linear operators in locally convex spaces, J. London Math. Soc., (2), 2 (1970), 493-503.

3. - Some special operators and new classes of locally convex spaces, Proc. Camb. Phil. Soc., 71 (1972), 475-489.

4. J. B. Conway, The strict topology and compactness in the space of measures, Bull. Amer. Math. Soc., 72 (1966), 75-78.

5. Ed Dubinsky and J. R. Retherford, Schauder bases and Köthe sequence spaces, Trans. Amer. Math. Soc., Vol. 130, No. 2, Feb. 1968, 265-280. 
6. T. Ito and T. Seidman, Bounded generators of linear spaces, Pacific J. Math., (1968), 283-286.

7. G. Köthe, Topological Vector Spaces I, (English translation by D. J. H. Garling of Topologische lineare Räume I 1966), Springer-Verlag, 1969.

8. A. Mallios, On functional representations of topological algebras, J. Funct. Anal., Vol. 6, No. 3, (1970), 468-480.

9. P. D. Morris and D. E. Wulbert, Functional representation of topological algebras, Pacific J. Math., 22 (1967), 323-337.

10. J. H. Webb, Sequential convergence in locally convex spaces, Proc. Camb. Phil. Soc., 64 (1968), 341-364.

11. A. Wiweger, Linear spaces with mixed topology, Studia Math., 20 (1961), 47-68.

Received April 25, 1972 and in revised form November 28, 1972.

Hindu College, University of Delhi, Delhi 7, India. 



\section{PACIFIC JOURNAL OF MATHEMATICS}

\section{EDITORS}

RICHARD ARENS (Managing Editor)

University of California

Los Angeles, California 90024

R. A. Beaumont

University of Washington

Seattle, Washington 98105
J. DUGUNDJI*

Department of Mathematics

University of Southern California

Los Angeles, California 90007

D. Gilbarg and J. Milgram

Stanford University

Stanford, California 94305

\section{ASSOCIATE EDITORS}
E. F. BECKENBACH
B. H. NeumanN
F. WOLF
K. YosHIDA

\section{SUPPORTING INSTITUTIONS}

UNIVERSITY OF BRITISH COLUMBIA
CALIFORNIA INSTITUTE OF TECHNOLOGY
UNIVERSITY OF CALIFORNIA
MONTANA STATE UNIVERSITY
UNIVERSITY OF NEVADA
NEW MEXICO STATE UNIVERSITY
OREGON STATE UNIVERSITY
UNIVERSITY OF OREGON
OSAKA UNIVERSITY

UNIVERSITY OF BRITISH COLUMBIA

UNIVERSITY OF CALIFORNIA

MONTANA STATE UNIVERSITY

UNIVERSITY OF NEVADA

OREGON STATE UNIVERSITY

OSAKA UNIVERSITY
UNIVERSITY OF SOUTHERN CALIFORNIA

STANFORD UNIVERSITY

UNIVERSITY OF TOKYO

UNIVERSITY OF UTAH

WASHINGTON STATE UNIVERSITY

UNIVERSITY OF WASHINGTON

\section{AMERICAN MATHEMATICAL SOCIETY} NAVAL WEAPONS CENTER

* C. R. DePrima California Institute of Technology, Pasadena, CA 91109, will replace J. Dugundji until August 1974. 


\section{Pacific Journal of Mathematics}

\section{Vol. 48, No. $1 \quad$ March, 1973}

Jan Aarts and David John Lutzer, Pseudo-completeness and the product of Baire

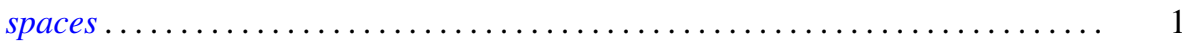

Gordon Owen Berg, Metric characterizations of Euclidean spaces ............ 11

Ajit Kaur Chilana, The space of bounded sequences with the mixed topology ..... . 29

Philip Throop Church and James Timourian, Differentiable open maps of

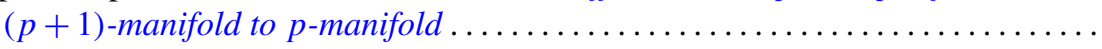

P. D. T. A. Elliott, On additive functions whose limiting distributions possess a finite

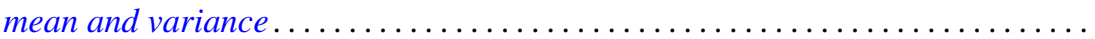

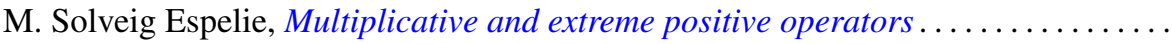

Jacques A. Ferland, Domains of negativity and application to generalized convexity

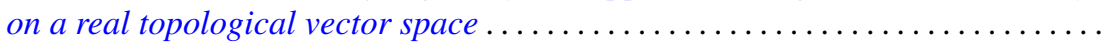

Michael Benton Freeman and Reese Harvey, A compact set that is locally holomorphically convex but not holomorphically convex ...............

Roe William Goodman, Positive-definite distributions and intertwining

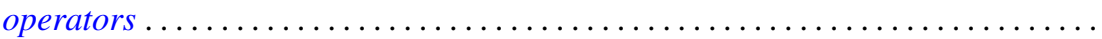

Elliot Charles Gootman, The type of some $C^{*}$ and $W^{*}$-algebras associated with

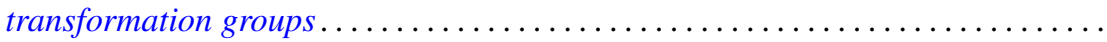

David Charles Haddad, Angular limits of locally finitely valent holomorphic

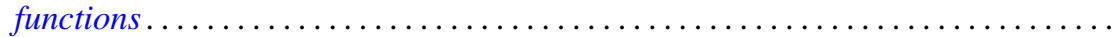

William Buhmann Johnson, On quasi-complements .

William M. Kantor, On 2-transitive collineation groups of finite projective spaces...

Joachim Lambek and Gerhard O. Michler, Completions and classical localizations of right Noetherian rings

Kenneth Lamar Lange, Borel sets of probability measures ......

David Lowell Lovelady, Product integrals for an ordinary differential equation in a Banach space

Jorge Martinez, A hom-functor for lattice-ordered groups .........

W. K. Mason, Weakly almost periodic homeomorphisms of the two sphere ....

Anthony G. Mucci, Limits for martingale-like sequences .......

Eugene Michael Norris, Relationally induced semigroups ...

Arthur E. Olson, A comparison of c-density and $k$-density ......

Donald Steven Passman, On the semisimplicity of group rings of linear groups.

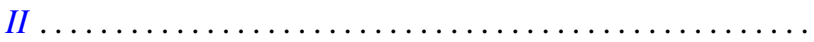

Charles Radin, Ergodicity in von Neumann algebras .

P. Rosenthal, On the singularities of the function generated by the Bergman operator of the second kind.

Arthur Argyle Sagle and J. R. Schumi, Multiplications on homogeneous spaces,

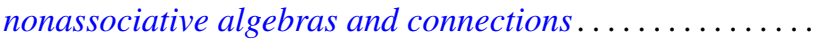

Leo Sario and Cecilia Wang, Existence of Dirichlet finite biharmonic functions on

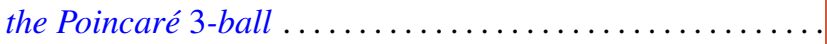

Ramachandran Subramanian, On a generalization of martingales due to Blake ..

Bui An Ton, On strongly nonlinear elliptic variational inequalities.

Seth Warner, A topological characterization of complete, discretely valued

fields. 